\title{
Prognostic significance of thyroid or cricoid cartilage invasion in laryngeal or hypopharyngeal cancer treated with organ preserving strategies
}

\author{
Marcus M Wagner ${ }^{1}$, Joel K Curé ${ }^{2}$, Jimmy J Caudell ${ }^{1,5}$, Sharon A Spencer ${ }^{1}$, Lisle M Nabell ${ }^{3}$, William R Carroll ${ }^{4}$ \\ and James A Bonner ${ }^{1 *}$
}

\begin{abstract}
Background: The utility of definitive radiotherapy (RT) for locoregionally advanced squamous cell carcinoma (SCC) of the larynx or hypopharynx in the setting of thyroid or cricoid cartilage invasion (TCCI) is controversial. A retrospective review of our experience was performed.

Methods: Our institutional database of patients with SCC of the head and neck treated with radiotherapy (90\% received concurrent systemic therapy) between 1995 and 2009 was queried. We identified 87 patients with T3-4 laryngeal or T4 hypopharyngeal cancer for whom initial head and neck imaging was available for review. Imaging of all patients was reviewed by a single radiologist specializing in neuroradiology. The presence and extent of TCCI was determined and used for stratification.

Results: Median follow-up was 34 months. TCCI was found in 25 (29\%) patients, eight limited to the inner cortex and another 17 involving both cortices. Local control (LC) was not significantly affected by TCCl limited to the inner cortex. However, TCCl involving both cortices was correlated with diminished LC at 2 years compared to the group of patients with no or minor invasion ( $55 \%$ vs. $81 \%, \mathrm{p}=0.045$ ). However, $\mathrm{TCCl}$ involving both cortices was not associated with significantly reduced rates of survival with a functional larynx, or overall survival (OS).

Conclusions: Our results suggest that the rate of LC of T3-4 laryngeal or T4 hypopharyngeal SCC treated with definitive RT is not affected by TCCl of the inner cortex. Although decreased LC was significantly associated with TCCl involving both cortices, this factor did not appear to result in reduced rates of survival with a functional larynx or OS. Therefore, organ preservation may remain an option in these patients.
\end{abstract}

Keywords: Thyroid, Cricoid, Cartilage, Invasion, Head and neck, Cancer, Local failure, Radiotherapy, Larynx, Hypopharynx

\section{Background}

Patients with thyroid or cricoid cartilage invasion (TCCI) of the larynx were included in the landmark Veteran's Administration (VA) Laryngeal Cancer Study Group trial which established the effectiveness of organ preservation for advanced laryngeal cancer using a regimen of induction cisplatin and 5-fluorouracil followed by radiotherapy (RT) [1]. Although there was a higher

\footnotetext{
*Correspondence: gesims@uabmc.edu

'Departments of Radiation Oncology, University of Alabama at Birmingham, Hazelrig-Salter Radiation Oncology Center, 1700 6th Avenue South, Birmingham, AL 35249-6832, USA

Full list of author information is available at the end of the article
}

rate of salvage laryngectomy in patients with gross cartilage invasion, this difference was not significant. However, T4 tumors in general had a 59\% risk of salvage laryngectomy, significantly higher than smaller tumors. The EORTC trial 24891 also tested a similar organ preservation scheme for locally advanced tumors of the pyriform sinus [2]. None of the four T4 patients randomized to induction chemotherapy achieved a complete response and were therefore diverted to definitive surgery.

Based on the findings of the VA and EORTC trials, the RTOG chose to exclude high volume T4 tumors in its largest laryngeal preservation trial, 91-11. High volume 
was defined as penetration through the cartilage or extending more than $1 \mathrm{~cm}$ into the base of the tongue [3]. In contrast, several European groups continued to include T4 lesions of the larynx and hypopharynx in organ preservation trials [4-7]. Given the uncertainty regarding feasibility of organ preservation in T4 laryngeal or hypopharyngeal cancers with TCCI, we retrospectively examined outcomes for this population at the University of Alabama at Birmingham.

\section{Methods}

The University of Alabama at Birmingham Department of Radiation Oncology database of patients with squamous cell carcinoma (SCC) of the head and neck treated with definite radiotherapy between 1995 and 2009 was queried. Patients were included in this study whose AJCC staging criteria (version 6.0) incorporated TCCI (T3-4 laryngeal SCC or T4 hypopharyngeal SCC), were 18 years old or older, received definitive radiotherapy (RT), and had pretreatment imaging of the neck with either computed tomography $(\mathrm{CT})$ or magnetic resonance imaging (MRI) that was available for review. Eightyseven patients remained for analysis. These patients did not undergo surgery due to various reasons. Patients were reviewed at a multidisciplinary conference and their preferences as well as co-morbidities were considered. Of the 87 patients, 27 were treated on chemoradiotherapy protocols.

A single radiologist (JKC), who specializes in neuroradiology, performed a detailed review of pre-treatment neck imaging to determine the presence or absence of TCCI. The extent of TCCI was further characterized as limited to the inner cortex (henceforth "minor TCCI") or invading into both inner and outer cortices with or without extralaryngeal spread (henceforth "major TCCI"). Examples are shown in Figure 1. Patients judged to solely have sclerosis of the cartilage or extralaryngeal

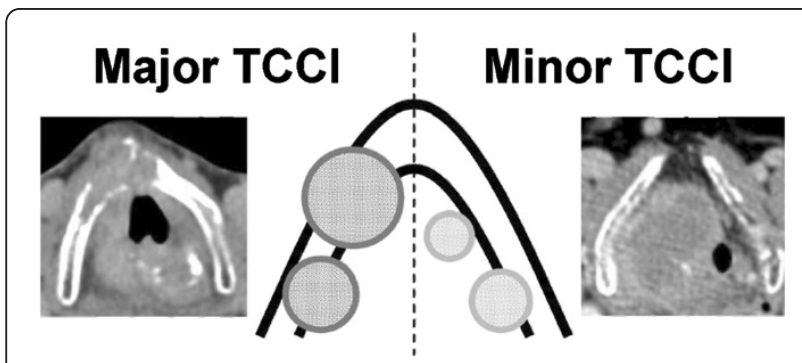

Figure 1 Illustration and CT images of major (left) and minor (right) thyroid or cricoid cartilage invasion (TCCI). The AJCC $7^{\text {th }}$ edition staging manual for laryngeal tumors classifies minor TCCI (i.e. invasion limited to the inner cortex) as T3 and major invasion (i.e. invasion into both inner and outer cortices) as T4. Both minor and major TCCl are staged as T4 for hypopharyngeal tumors. spread without cartilage invasion were not considered to have TCCI.

Treatment techniques for this patient population have been reported previously [8]. Briefly, all patients were immobilized with a thermoplastic head and neck mask and underwent CT simulation. Patients were planned using 3-dimensional treatment planning or intensity modulated radiation therapy (IMRT) with 6-megavolt photons. In this group of 87 patients, 16 patients had tracheostomies prior to radiation and this procedure was primarily performed for stabilization of the airway. Induction and concurrent chemotherapy consisted of a platinum agent with or without a taxane or fluorouracil. The anti-EGFR monoclonal antibody cetuximab was occasionally utilized with definitive radiation as previously described [8].

Patient characteristics were compared using the Chisquare test. All endpoints were calculated from the start of radiotherapy. Local control (LC), laryngectomy-free survival (LFS; defined as surviving patients without laryngectomy), laryngo-esophageal dysfunction-free survival (LEDFS; defined as surviving patients without local relapse, total or partial laryngectomy, or tracheotomy or feeding tube at two years or later as previously discribed [9]), and overall survival (OS) were calculated using the Kaplan-Meier method with the log rank test for comparisons. Statistical analyses were performed with SPSS version 19.0 (IBM Company, New York, USA).

\section{Results}

Median follow-up for the 87 eligible patients was 34 months. Patient, tumor, and treatment characteristics are listed in Table 1. Median RT dose to the gross disease was 70.2 Gy (range 65.4 - 76.8 Gy). TCCI was found in 25 (29\%) patients, eight with minor TCCI and 17 with major TCCI. The thyroid cartilage alone was involved in 18 patients, cricoid cartilage alone in two patients, and both in five patients. All but two cases of minor TCCI had extension of the primary disease beyond the larynx qualifying these tumors as T4.

Local failure occurred in 10 of 62 patients without TCCI, 1 of 8 patients with minor TCCI, and 6 of 17 patients with major TCCI. Two year LC was $80 \%$ $( \pm 5.8 \%$ standard error) without TCCI, 86\% $( \pm 13.2 \%$ standard error) with minor TCCI, and 55\% ( $\pm 13.8 \%$ standard error) with major TCCI (Table 2; $>>0.05$ for all comparisons). The patients with no TCCI or minor TCCI were found to have significantly higher 2 year LC compared to those with major TCCI $(81 \%$ vs. $55 \%$, $\mathrm{p}=0.045$, Figure 2). Within the subset of patients with T4 disease (43 patients), major cartilage invasion (versus all other T4 cases) was not significantly associated with worse LC ( $55 \%$ vs. $78 \%, \mathrm{p}=0.16)$. The six patients from the major TCCI group who had local failures did 
Table 1 Patient, Tumor, and Treatment characteristics

\begin{tabular}{lcc}
\hline Characteristic & All Patients $(\mathbf{n}, \mathbf{0})$ & Any Invasion \\
\hline Total & $87(100)$ & $25(29)$ \\
\hline Gender & $68(78)$ & $19(76)$ \\
\hline Male & $19(22)$ & $6(24)$ \\
\hline Female & $\begin{array}{c}\text { Median }=57 \text { years } \\
\text { (range } 33-81)\end{array}$ & $\begin{array}{c}\text { Median }=58 \text { years } \\
\text { (range } 41-81)\end{array}$ \\
\hline Age & $49(56)$ & $13(52)$ \\
\hline Ethnicity & $38(44)$ & $12(48)$ \\
\hline Caucasian/Other & & $21(84)$ \\
\hline African-American & $73(84)$ & $4(16)$ \\
\hline KPS score & $14(16)$ & \\
\hline $50-80$ &
\end{tabular}

Primary site with T-

stage

\begin{tabular}{|c|c|c|}
\hline Larynx & $78(90)$ & $21(84)$ \\
\hline T3 & $44(51)$ & $2(8)$ \\
\hline $\mathrm{T4a}$ & $30(34)$ & $18(72)$ \\
\hline $\mathrm{T} 4 \mathrm{~b}$ & $4(5)$ & $1(4)$ \\
\hline Hypopharynx & $9(10)$ & $4(16)$ \\
\hline T4 & $8(9)$ & $4(16)$ \\
\hline $\mathrm{T4b}$ & $1(1)$ & $0(0)$ \\
\hline \multicolumn{3}{|l|}{$\mathrm{N}$-stage } \\
\hline No & $34(39)$ & $11(44)$ \\
\hline N1 & $11(13)$ & $6(24)$ \\
\hline N2 & $35(40)$ & $5(20)$ \\
\hline N3 & $7(8)$ & $3(12)$ \\
\hline \multicolumn{3}{|l|}{ Overall Stage } \\
\hline III & $24(28)$ & $1(4)$ \\
\hline IVA & $53(61)$ & $20(80)$ \\
\hline IVB & $10(11)$ & $4(16)$ \\
\hline \multicolumn{3}{|c|}{ Concurrent Therapy } \\
\hline None & $9(10)$ & $2(8)$ \\
\hline Cetuximab & $6(7)$ & $1(4)$ \\
\hline $\begin{array}{l}\text { Cytotoxic } \\
\text { Chemotherapy }\end{array}$ & $72(83)$ & $22(88)$ \\
\hline \multicolumn{3}{|l|}{$\begin{array}{l}\text { Neoadjuvant } \\
\text { Chemotherapy }\end{array}$} \\
\hline No & $75(86)$ & $21(84)$ \\
\hline Yes & $12(14) *$ & $4(16)$ \\
\hline \multicolumn{3}{|c|}{ Fractionation of RT } \\
\hline Conventional & $39(45)$ & $9(36)$ \\
\hline $\begin{array}{l}\text { Altered } \\
\text { Fractionation }\end{array}$ & $48(55)$ & $16(64)$ \\
\hline \multicolumn{3}{|l|}{ IMRT } \\
\hline Yes & $52(60)$ & $15(60)$ \\
\hline No & $35(40)$ & $10(40)$ \\
\hline \multicolumn{3}{|l|}{ Local Recurrence } \\
\hline Yes & $17(20)$ & 7 (28) \\
\hline
\end{tabular}

Table 1 Patient, Tumor, and Treatment characteristics (Continued)

\begin{tabular}{lcc}
\hline No & $70(80)$ & $18(72)$ \\
\hline $\begin{array}{l}\text { Regional } \\
\text { Recurrence }\end{array}$ & & \\
\hline Yes & $5(6)$ & $1(4)$ \\
\hline $\begin{array}{l}\text { Synchronous with } \\
\text { LR }\end{array}$ & $3(60)$ & $1(100)$ \\
\hline Isolated & $2(40)$ & $0(0)$ \\
\hline No & $82(94)$ & $24(96)$ \\
\hline Distant Metastasis & & $4(16)$ \\
\hline Yes & $16(18)$ & $21(84)$ \\
\hline No & $71(82)$ & \\
\hline
\end{tabular}

* 11 of 12 received concurrent chemoradiotherapy after induction and one received radiotherapy alone.

not have synchronous distant failures (though one had a synchronous regional failure) and were able to undergo salvage laryngectomy. Three of these patients were without evidence of recurrent disease more than two years after salvage surgery.

Although major TCCI was associated with decreased $\mathrm{LC}$, there was no significant difference in rates of LFS at 2 years. The LFS for major TCCI was $41 \%$ compared to $58 \%$ for none/minor TCCI $(\mathrm{p}=0.31)$. In addition, the LEDFS at 2 years for major TCCI was $34 \%$ compared to $44 \%$ for none/minor TCCI ( $\mathrm{p}=0.38$; Table 3). As shown in Figure 3, no difference in OS was found between major TCCI (65\%) and no/minor TCCI (64\%).

\section{Discussion}

This study of patients with T3/T4 laryngeal cancer and T4 hypopharyngeal cancer revealed that major TCCI was a poor prognostic factor regarding LC and not LFS, LEDFS, or OS. Furthermore, within the subset of T4 tumors, major TCCI was not a significant predictor of worse LC. However, this latter analysis of T4 patients was limited due to small numbers of patients in this subgroup. Our results suggest that it may be reasonable to offer organ preservation with CRT for motivated patients with major TCCI. This proposal is based on the fact that patients who fail organ preservation have good salvage options and the lack of evidence that upfront surgery provides improved survival outcomes.

These results are supported by other reports of organ preservation strategies for advanced laryngeal and hypopharyngeal tumors. For example, Do et al. [10] retrospectively analyzed 101 patients with stage T4 head and neck cancers treated with definitive RT or resection, from several centers associated with the University of California Davis. Subset analysis of the CRT group found no differences in LC $(50 \%$ and $56 \%$ at 5 years, 
Table 2 Local Control and Overall Survival at 2 years

\begin{tabular}{|c|c|c|c|c|c|}
\hline & \# of patients & Local control & $P$ value & Overall Survival & $P$ value \\
\hline All patients & 87 & $76 \%$ & & $64 \%$ & \\
\hline Any TCCl & 25 & 65 & 0.15 & 64 & 0.86 \\
\hline No TCCl & 62 & 80 & & 65 & \\
\hline Minor TCCl & 8 & 86 & 0.87 & 63 & 0.97 \\
\hline No TCCl & 62 & 80 & & 65 & \\
\hline Major TCCI & 17 & 55 & 0.045 & 65 & 0.82 \\
\hline No or minor $\mathrm{TCCl}$ & 70 & 81 & & 64 & \\
\hline
\end{tabular}

respectively) or OS in 26 patients with bone and/or cartilage invasion compared to 42 patients with other T4 criteria. The same group later demonstrated no difference between bone or cartilage invasion [11]. Samant et al. [12] also reported no difference in outcomes based on bone versus cartilage invasion in 45 patients treated with intra-arterial cisplatin and concurrent RT (CRT). In contrast, Huang et al. [13] reported that patients with cricoid cartilage invasion had decreased 5 year OS (LC data not provided) based on multivariate analysis of 47 patients with hypopharyngeal cancer.

Various strategies are currently being tested to optimize the selection of patients for organ preservation. The University of Michigan [14] studied the combined results of two phase II trials in 36 patients with major TCCI by employing a chemoselection regimen. Treatment with CRT or surgery was determined by response to a single cycle of cisplatin and fluorouracil.
After one cycle of chemotherapy, $81 \%$ of patients had a $\geq 50 \%$ response. These responders underwent CRT yielding $58 \%$ LFS and $78 \%$ OS at 3 years. Other groups have employed this same response-based approach and have found encouraging results in selective organ preservation based on restaging biopsies $[15,16]$ or functional imaging [17] during CRT. Others have suggested that selection based on initial tumor volume [18] or pre-treatment laryngeal function [9] may be reasonable strategies. Further study of these innovative organ preserving strategies is warranted in the setting of locoregionally advanced head and neck cancers with cartilage invasion.

It is noteworthy that TCCI is commonly misdiagnosed by CT imaging. Beitler et al. [19] compared preoperative imaging with the results of subsequent surgical pathology following laryngectomy. Of the 107 clinically staged T4 laryngeal tumors, CT imaging correctly

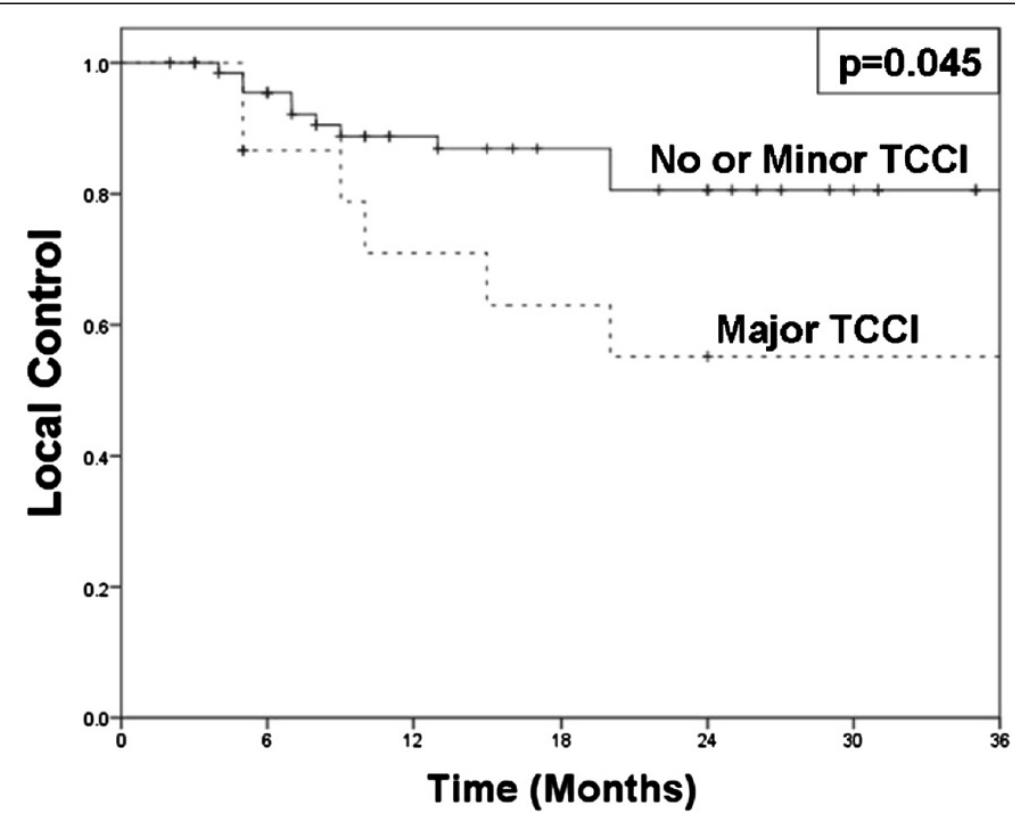

Figure 2 Kaplan-Meier curves for local control comparing no or minor TCCI (solid) versus major TCCI (dashed). Two-year local control for patients with no or minor TCCI was $81 \%$ compared to $55 \%$ with major TCCI $(p=0.045)$. 
Table 3 Organ Preservation at 2 years

\begin{tabular}{|c|c|c|c|c|}
\hline & Laryngectomy-free survival & $P$ value & Laryngo-esophageal dysfunction-free survival & $P$ value \\
\hline All patients & $55 \%$ & & $41 \%$ & \\
\hline Any TCCl & 44 & 0.28 & 35 & 0.45 \\
\hline No TCCl & 60 & & 44 & \\
\hline Minor & 50 & 0.64 & 38 & 0.87 \\
\hline No TCCl & 60 & & 44 & \\
\hline Major TCCI & 41 & 0.31 & 34 & 0.38 \\
\hline No or minor $\mathrm{TCCl}$ & 58 & & 44 & \\
\hline
\end{tabular}

identified only $59 \%$ of cases with major cartilage invasion without extralaryngeal spread and $49 \%$ of cases with extralaryngeal spread [positive predictive values (PPV) $74 \%$ and $81 \%$, respectively]. A similar study by Li et al. [20] reported only $60 \%$ identification of major cartilage invasion (100\% if extralaryngeal spread was present) with CT imaging. Additionally, $47 \%$ of tumors identified as T4 by CT were downstaged to T3 after pathologic review. Determination of TCCI using MRI may have a higher detection rate for intracartilagenous invasion but is a costly and limited resource that is prone to false positive results [21]. We attempted to minimize our potential misinterpretation of TCCI by excluding findings of cartilage sclerosis and extralargyngeal spread without cartilage invasion and by systemically reanalyzing pretreatment images.

Our results are subject to the inherent limitations of any retrospective review. First, only 17 patients had major cartilage invasion. Second, the occasional use of simulation scans, when diagnostic scans were not available, may have limited the detection rate of TCCI. Third, organ preservation therapy precludes pathologic review as the gold standard for determination of TCCI. With these noted caveats, the current analysis suggests that organ preservation strategies can be considered in patients with TCCI.

\section{Conclusions}

Major TCCI were associated with decreased LC, but not LFS, LEDFS, or OS. These patients tend to fail locally (without distant spread) and are good candidates for salvage surgery. Without a clear survival advantage to initial surgery in this population, organ preservation may still be a reasonable treatment option.

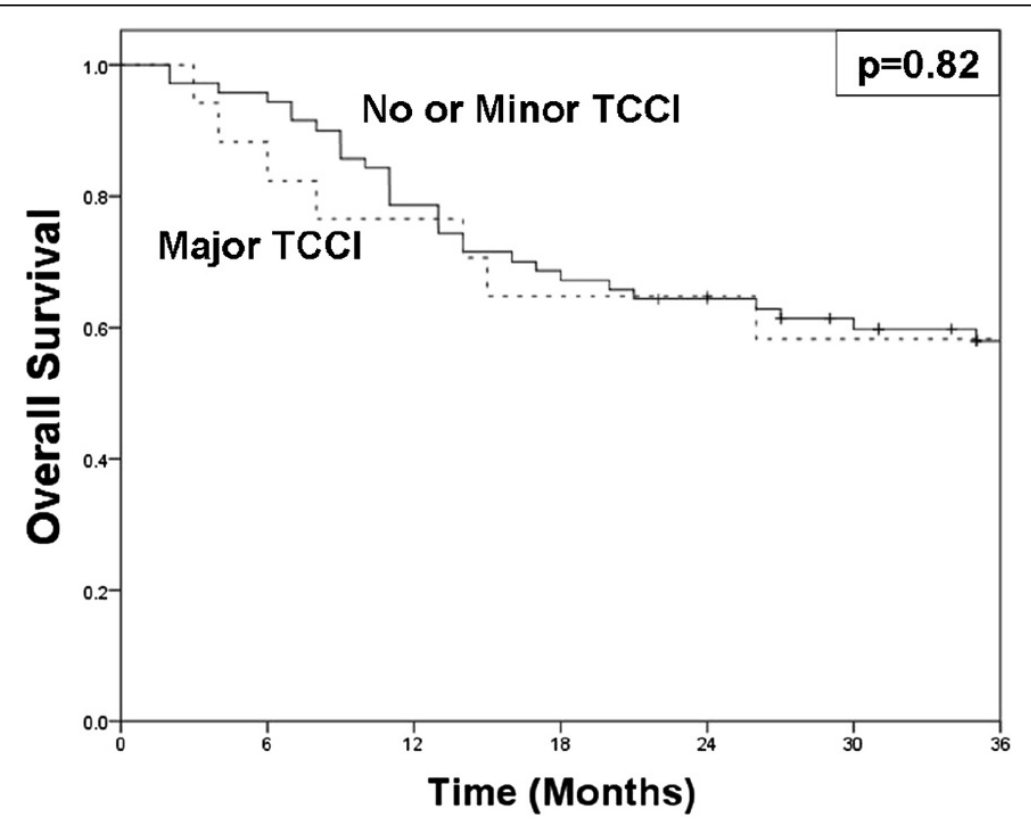

Figure 3 Kaplan-Meier curves for overall survival comparing overall survival for no or minor TCCI (solid) versus major TCCI (dashed). Two-year overall survival for patients with no or minor TCCI was $64 \%$ and $65 \%$ for major TCCI $(p=0.82)$. 


\section{Competing interests}

Drs. Wagner, Curé, Caudell, Spencer, Carroll, and Nabell: Actual or potential conflicts of interest do not exist.

Dr. Bonner: Occasional consultant / honoraria for Astra Zeneca, Bristol-Myers Squibb Company, Eli Lilly and Company, Genmab, ImClone Systems, Inc., Merck Serono, Oncolytics, Sanofi-Aventis and AVEO.

\section{Authors' contributions}

MMW, JJC and JAB are responsible for study conception and design. MMW $J K C, J J C$ and JAB participated in data collection and interpretation. MMW and $J J C$ were responsible for statistical evaluation. All authors are responsible for manuscript writing. MMW, JJC and JAB are responsible for assembly of all figures and tables. All authors are in agreement with the content submitted herein. All authors read and approved the final manuscript.

\section{Acknowledgements}

The authors would like to acknowledge Gwen Sims for preparation of this manuscript.

\section{Author details}

${ }^{1}$ Departments of Radiation Oncology, University of Alabama at Birmingham, Hazelrig-Salter Radiation Oncology Center, 1700 6th Avenue South, Birmingham, AL 35249-6832, USA. ²Departments of Radiology, University of Alabama at Birmingham, Birmingham, AL, USA. ${ }^{3}$ Departments of Medicine, and Otolaryngology, University of Alabama at Birmingham, Birmingham, AL, USA. ${ }^{4}$ Departments of Otolaryngology, University of Alabama at Birmingham, Birmingham, AL, USA. ${ }^{5}$ Department of Radiation Oncology, Moffitt Cancer Center, Tampa, FL, USA.

Received: 4 September 2012 Accepted: 12 December 2012 Published: 21 December 2012

\section{References}

1. Induction chemotherapy plus radiation compared with surgery plus radiation in patients with advanced laryngeal cancer. The department of veterans affairs laryngeal cancer study group. N Engl J Med 1991, 324:1685-1690.

2. Lefebvre JL, Chevalier D, Luboinski B, et al: Larynx preservation in pyriform sinus cancer: preliminary results of a european organization for research and treatment of cancer phase III trial. EORTC Head and Neck Cancer Cooperative Group. J Natl Cancer Inst 1996, 88:890-899.

3. Forastiere AA, Goepfert H, Maor M, et al: Concurrent chemotherapy and radiotherapy for organ preservation in advanced laryngeal cancer. N Engl J Med 2003, 349:2091-2098.

4. Lefebvre JL, Rolland F, Tesselaar M, et al: Phase 3 randomized trial on larynx preservation comparing sequential vs alternating chemotherapy and radiotherapy. J Natl Cancer Inst 2009, 101:142-152.

5. Lorch JH, Goloubeva O, Haddad Rl, et al: Induction chemotherapy with cisplatin and fluorouracil alone or in combination with docetaxel in locally advanced squamous-cell cancer of the head and neck: long-term results of the TAX 324 randomised phase 3 trial. Lancet Oncol 2011, 12:153-159.

6. Pointreau Y, Garaud P, Chapet $S$, et al: Randomized trial of induction chemotherapy with cisplatin and 5-fluorouracil with or without docetaxel for larynx preservation. J Natl Cancer Inst 2009, 101:498-506.

7. Vermorken JB, Remenar E, van Herpen C, et al: Cisplatin, fluorouracil, and docetaxel in unresectable head and neck cancer. N Engl J Med 2007, 357:1695-1704.

8. Caudell JJ, Schaner PE, Meredith RF, et al: Factors associated with long-term dysphagia after definitive radiotherapy for locally advanced head-and-neck cancer. Int J Radiat Oncol Biol Phys 2009, 73:410-415.

9. Caudell JJ, Carroll WR, Spencer SA, et al: Examination of laryngoesophageal dysfunction-free survival as an endpoint in nonsurgical treatment of squamous cell carcinomas of the larynx and hypopharynx. Cancer 2011, 117:4447-4451.

10. Do L, Puthawala A, Syed N, et al: Treatment outcomes of T4 locally advanced head and neck cancers with soft tissue invasion or bone and cartilage invasion. Am J Clin Oncol 2009, 32(5):477-482.

11. Do L, Syed N, Puthawala A, et al: Prognostic significance of bone or cartilage invasion of locally advanced head and neck cancers. Am J Clin Oncol 2010, 33:591-594.
12. Samant $\mathrm{S}$, Robbins $\mathrm{KT}$, Kumar $\mathrm{P}$, et al: Bone or cartilage invasion by advanced head and neck cancer: intra-arterial supradose cisplatin chemotherapy and concomitant radiotherapy for organ preservation. Arch Otolaryngol Head Neck Surg US 2001, 127(12):1451-1456.

13. Huang $W Y$, Jen $Y M$, Chen CM, et al: Intensity modulated radiotherapy with concurrent chemotherapy for larynx preservation of advanced resectable hypopharyngeal cancer. Radiat Oncol England 2010, 37.

14. Worden FP, Moyer J, Lee JS, et al: Chemoselection as a strategy for organ preservation in patients with T4 laryngeal squamous cell carcinoma with cartilage invasion. Laryngoscope 2009, 119:1510-1517.

15. Wanebo HJ, Rathore R, Chougule P, et al: Selective Organ Preservation in Operable Locally Advanced Head and Neck Squamous Cell Carcinomas Guided by Primary Site Restaging Biopsy: Long-Term Results of Two Sequential Brown University Oncology Group Chemoradiotherapy Studies. Ann Surg Oncol 2011, 18(12):3479-3485.

16. Yom SS, Machtay M, Biel MA, et al: Survival impact of planned restaging and early surgical salvage following definitive chemoradiation for locally advanced squamous cell carcinomas of the oropharynx and hypopharynx. Am J Clin Oncol US 2005, 28(4):385-392.

17. Hentschel M, Appold S, Schreiber A, et al: Early FDG PET at 10 or 20 Gy under chemoradiotherapy is prognostic for locoregional control and overall survival in patients with head and neck cancer. Eur J Nucl Med Mol Imaging 2011, 38:1203-1211.

18. Strongin A, Yovino S, Taylor R, et al: Primary tumor volume is an important predictor of clinical outcomes among patients with locally advanced squamous cell cancer of the head and neck treated with definitive chemoradiotherapy. Int J Radiat Oncol Biol Phys 2011, 82(5):1823-1830.

19. Beitler JJ, Muller S, Grist WJ, et al: Prognostic accuracy of computed tomography findings for patients with laryngeal cancer undergoing laryngectomy. J Clin Oncol 2010, 28:2318-2322.

20. Li B, Bobinski M, Gandour-Edwards R, et al: Overstaging of cartilage invasion by multidetector $C T$ scan for laryngeal cancer and its potential effect on the use of organ preservation with chemoradiation. $\mathrm{Br} J$ Radiol 2011, 84:64-69.

21. Becker M, Zbaren P, Casselman JW, et al: Neoplastic invasion of laryngeal cartilage: reassessment of criteria for diagnosis at MR imaging. RSNA: Radiology US; 2008:551-559.

\section{doi:10.1186/1748-717X-7-219}

Cite this article as: Wagner et al:: Prognostic significance of thyroid or cricoid cartilage invasion in laryngeal or hypopharyngeal cancer treated with organ preserving strategies. Radiation Oncology 2012 7:219.

\section{Submit your next manuscript to BioMed Central and take full advantage of:}

- Convenient online submission

- Thorough peer review

- No space constraints or color figure charges

- Immediate publication on acceptance

- Inclusion in PubMed, CAS, Scopus and Google Scholar

- Research which is freely available for redistribution 